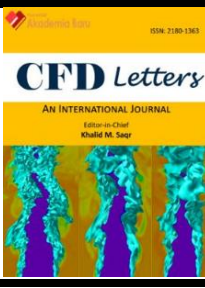

\title{
Computational Fluid Dynamics Analysis of Rigs-to-Reefs (R2R) Jacket Structures
}

\author{
Mohd Asamudin A. Rahman ${ }^{1}$, Muhammad Nadzrin Nazri ${ }^{1}$, Fatin Alias ${ }^{1}$, Ahmad Fitriadhy ${ }^{1}$, Mohd \\ Hairil Mohd ${ }^{1, *}$ \\ 1 Faculty of Ocean Engineering Technology and Informatics, Universiti Malaysia Terengganu, 21030 Kuala Nerus, Terengganu, Malaysia
}

\section{ARTICLE INFO}

\section{Article history:}

Received 23 November 2020

Received in revised form 18 January 2021

Accepted 23 January 2021

Available online 31 January 2021

\section{ABSTRACT}

Platform decommissioning activities have been increasing due to unproductive fields and unstable oil prices. One of the decommissioning methods used by the oil and gas companies is by converting the platform into an artificial reef through the rigs-to-reef $(\mathrm{R} 2 \mathrm{R})$ programme. The programme benefits the marine life and increases the marine productions. In this study, the dynamic responses and flow characteristics of jacket platforms were investigated using computational fluid dynamics (CFD) analysis. Three jacket structures with different sizes were used to investigate the suitability of the structure as a potential artificial reef. The pressure exerted on the structure as well as the back eddies and upwelling phenomenon were also investigated. This is to ensure the settlement of the coral larvae and attract marine life to inhabit around the artificial reef. The results show that the platform size and configurations are the significant criteria to design any artificial reef. The pressure on the jacket member is in the acceptable range. Higher efficiency index of back eddy and upwelling could also be obtained by smaller jacket structures.

\section{Keywords:}

Rigs-to-reefs; artificial reef; CFD

simulation; upwelling; back eddy

\section{Introduction}

The rigs-to-reefs (R2R) programme provides an alternative to complete rig removals in decommissioning activities. In the programme, oil and gas companies select a platform to be modified into an artificial reef to support the marine life. Through the decommissioning process, the platform is either towed, toppled in place, or removed [1]. Figure 1 shows an example of artificial reef deployed in Sarawak, known as Kenyalang Reef [2]. However, not all platforms are suitable as reefing candidates. For any platform to be considered for reefing, the platform must first undergo extensive ecological and structural evaluations to assess any potential value that it might add to the local ecosystem for its stability and suitability. The structural evaluations of the platform consist of structural integrity assessment and artificial reef performance.

\footnotetext{
* Corresponding author.

E-mail address: m.hairil@umt.edu.my (Mohd Hairil Mohd)
} 


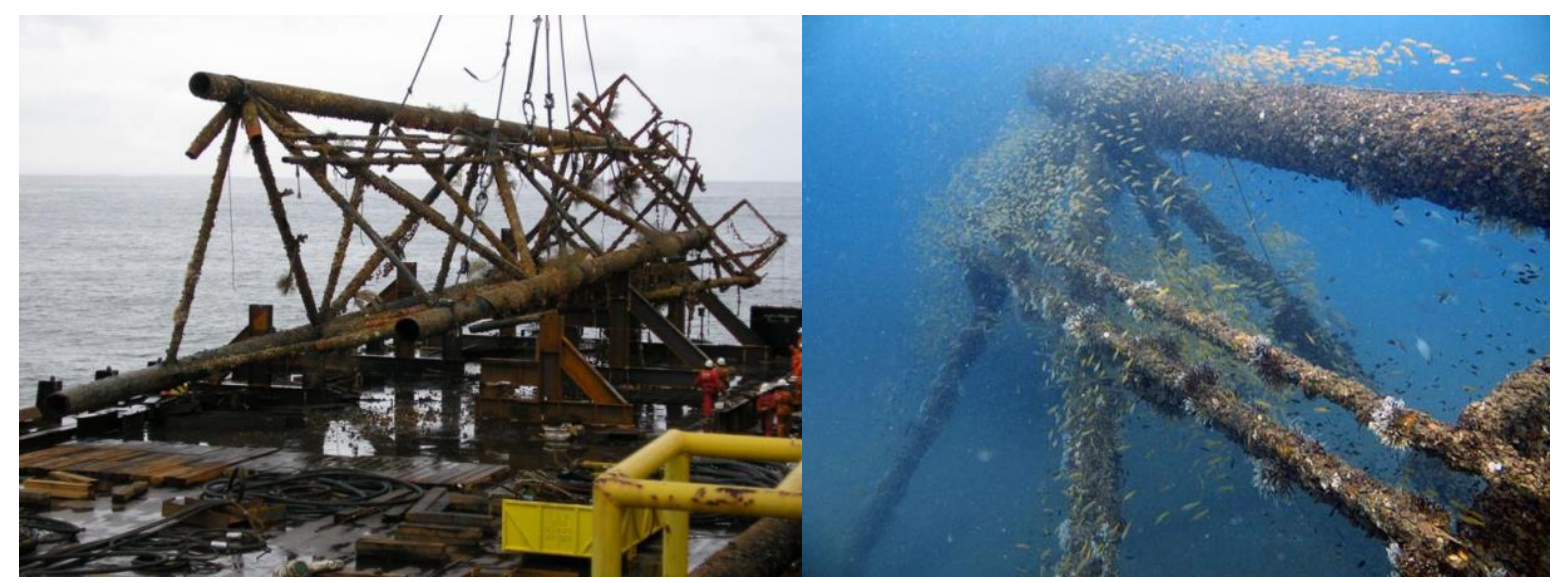

Fig. 1. Kenyalang reef deployed at Baram site, Sarawak, Malaysia [2]

Recently, Yaakob et al., [3] studied the hydrodynamic characteristics of a new type of artificial reef structure to provide a structure with low flow resistance, which will be a more suitable shelter for fishes and marine organisms. They found that the changing water depth has no effect on the drag force on the structure. A comprehensive investigation was also conducted on the flow direction towards two types of artificial reef: helmet shape and hollow cube. The Ansys CFX software was used to investigate the drag force of the artificial reefs (ARs) in three current directions: $0^{\circ}, 45^{\circ}$, and $90^{\circ}$. The result shows that the drag force increased from $0^{\circ}$ to $90^{\circ}$ due to the streamline effect and higher frontal area of the structure.

The resultant hydrodynamic forces are obtained by integrating the pressure forces over the surface of the cylinder [4]. According to Sumer \& Fredsoe [5], as the fluid flow over a cylinder, the fluctuation of pressure caused by surface roughness, cross-sectional shape, turbulence, and the shear in the incoming flow. The pressure distribution undergoes a periodic change because the shedding process progresses, resulting in a periodic variation in the force component. The main characteristic of the measured pressure distributions is that the pressure at the rear side of the cylinder (wake region) is always negative. This is due to the separation of the boundary layer and reverse flow region [6]. The negative values cause downward lift coefficient of downforce, which results in a negative value as mentioned by Dandan et al., [7]. Pranesh et al., [8] also noted that in such cases, the pressure on the front surface is greater than the pressure on the back surface for a significant part of the cylinder, leading to the generation of net negative lift. This phenomenon occurs when the reverse flow region is developed in the wake region [9-12].

Yonemoto et al., [13] described that the wake region is a region where a flow recirculating behind a moving or stationary object caused by the surrounding flow. The current flow is considered as one the most important factors affecting reef stability and performance. The reef performance represents the wake region produced by the structure. The wake phenomenon is favoured by the fish because it has a complex flow environment $[14,15]$. The wake region provides shelter, feeding grounds, spawning grounds, rest areas, and a temporary stopover for marine species [16]. It can be divided into two regions: upwelling and back eddy. The ARs deployed on the sea bottom can also act as physical barriers by inducing changes in bottom current intensity and direction, water flow, and turbulence patterns. This promotes upwelling, bringing nutrient rich AR bottom benthic waters compared to control areas, into the water column, thereby enhancing biological production. Kim et al., [17] and Wang et al., [18] also compared the upwelling speed according to different AR shapes. Figure 2 illustrates the definition of wake region by Kim et al. [17]. 


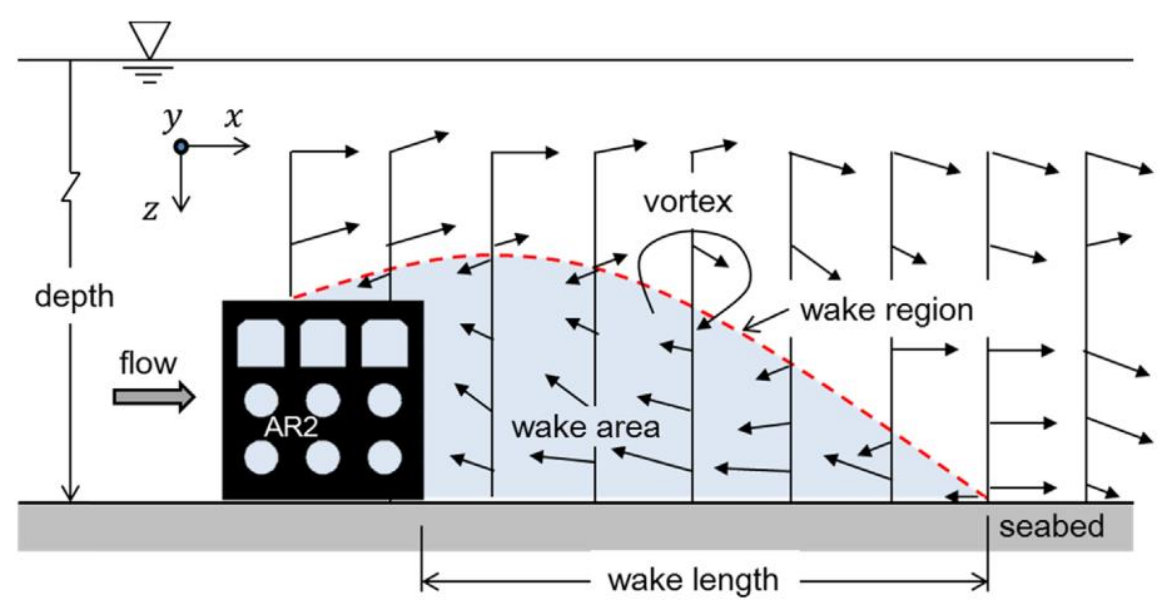

Fig. 2. Definition of the wake region [17]

The performance of a wake region can be classified in several ways. The first way is by its size, which is related to its efficiency. The second performance index is the speed of the recirculating water flow, which is related to the tranquility in the wake region. This index is important because the low recirculating water velocity in the wake region helps marine species to settle and optimise their net energy expenses. To the authors' knowledge, the study on the effects of structural configurations of R2R is still lacking. Hence, this study will evaluate the stability and suitability of different jacket structures as an artificial reef when deployed on seabed. This paper presents the dynamic responses and flow characteristics of different structural configurations for optimal coral growth to study the artificial reefs performance. It is a continuous study from a published paper by Rahman et al., [19].

\section{Methodology}

\subsection{Platform Description}

In this study, three jacket platforms with different sizes were considered. Platforms A, B, and C are a 3-legged existing jacket platform located at Malaysian water in water depth of approximately 28 to 80 m below mean sea level. Table 1 shows the detailed dimension of Platforms A, B, and C. For reefing purposes, the nonstructural components such as conductors, risers, and topside were removed before the jacket is laid down on the seabed as illustrated in Figure 3. Simulations were conducted for different current directions as shown in Figure 4.

Table 1

\begin{tabular}{lll}
\multicolumn{3}{l}{ Platform details } \\
\hline Platform & Height $(\mathrm{m})$ & Width $(\mathrm{m})$ \\
\hline A & 28.48 & 7.79777 \\
B & 62.18 & 13.05082 \\
C & 79.07 & 20.27294 \\
\hline
\end{tabular}

The geometry configuration, grid discretisation, computational configuration, and grid sensitivity studies published by Rahman et al., [19] were also referred to when necessary. 


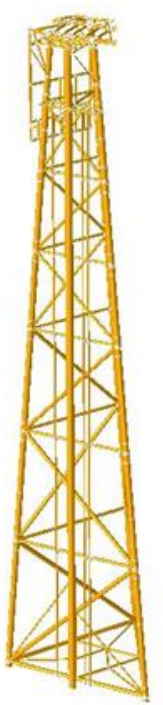

(a)

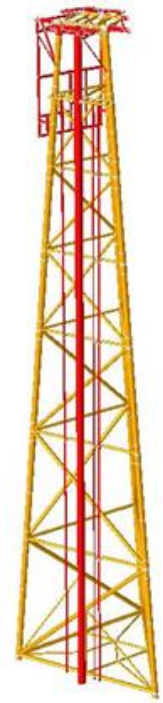

(b)

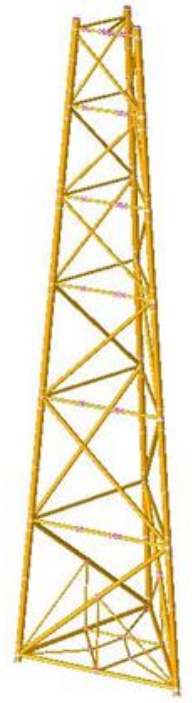

(c)

Fig. 3. The illustration of nonstructural components removal: (a) platform before removal, (b) highlighted nonstructural components for removal, and (c) jacket structure after removal.

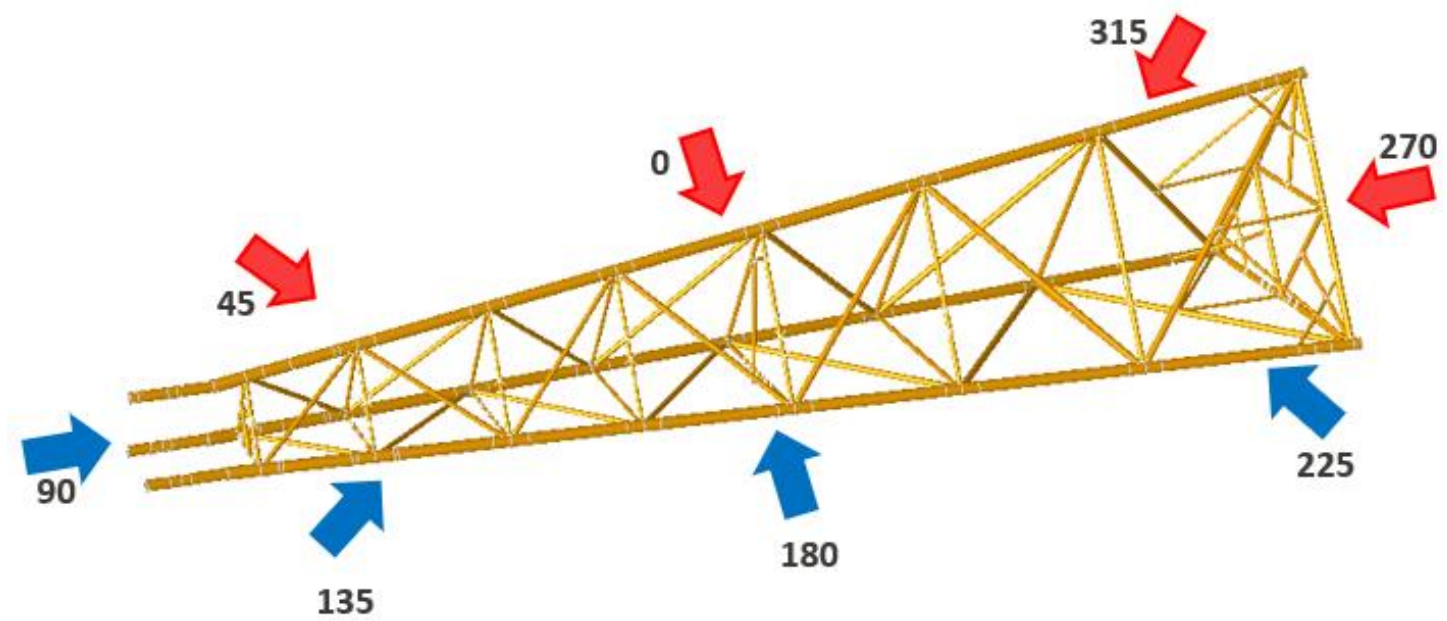

Fig. 4. Directionality for platform $A, B$ and $C$

\section{Results}

\subsection{Pressure Description}

The pressure value is significant on the ability of coral larvae to settle and grow on the R2R platforms. The ability of the organism to withstand the pressure on the structure up to some extent were discussed by Rahman et al., [19]. Table 2 shows the static pressure contour regime of the platforms. Figure 5 shows the maximum pressure value on Platforms $A, B$, and $C$ for different current directions. Platform $C$ has the highest pressure among the platforms. This is because, the jacket legs which are circular cylinder structure of Platform $\mathrm{C}$ was bigger than those of the other platforms. The maximum pressure was $6.753 \times 10^{2} \mathrm{~Pa}$ on Platform $\mathrm{C}$ at $270^{\circ}$ current direction, which can be considered low compared to the range of pressure from the literature which is around $10 \times 10^{4} \mathrm{~Pa}$ for biofouling detachment. This indicates the potential of coral to settle and grow on Platform $\mathrm{C}$ in the current sea condition. Therefore, the separation of flow of Platform $\mathrm{C}$ was also better than that 
of the other platforms. As manifested in the graph, the peak static pressure region of the platform is indicated in red. It is notable that, the structure the widely enveloped by orange and yellow contour regions, which evidently falls within the regions of low-pressure region.

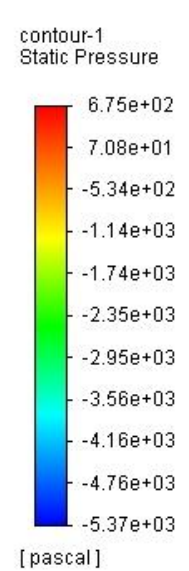

(a)
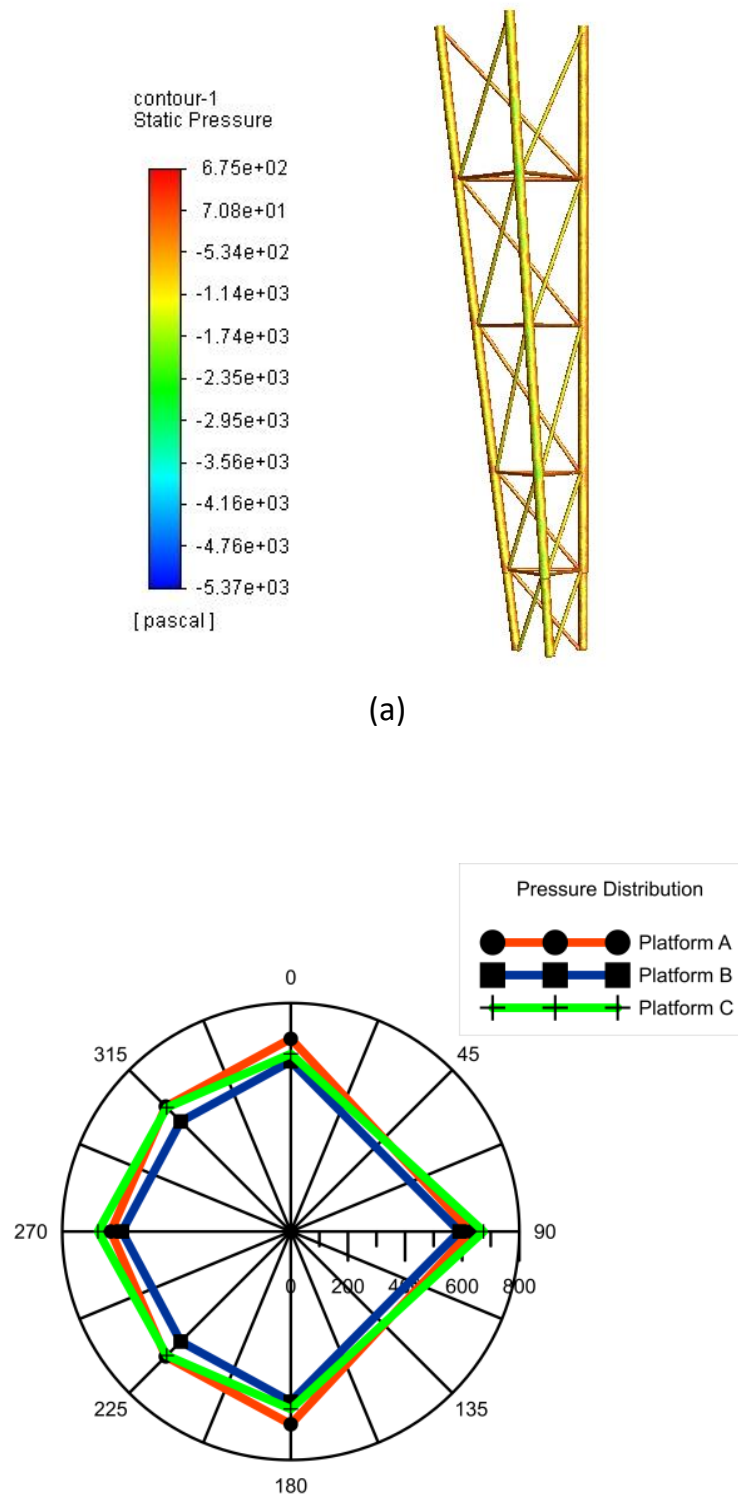

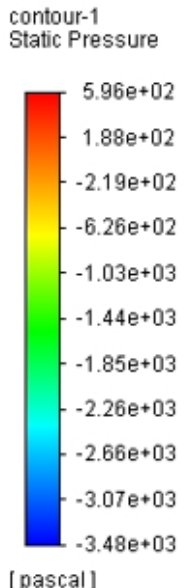

[pascal]

(b)
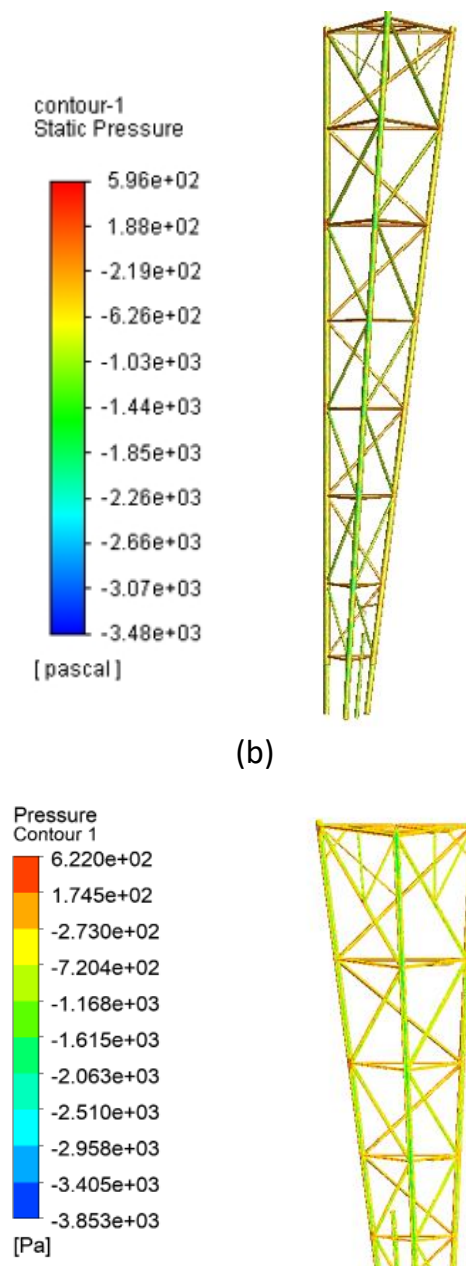

(c)

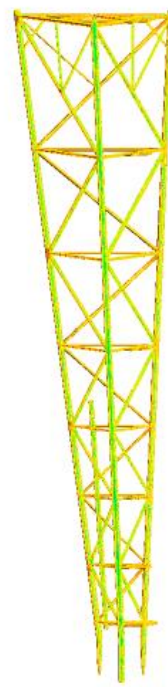

(c) Platform C (d)

Fig. 5. Static Pressure Contour at $0^{\circ} / 180^{\circ}$
Pressure distribution plot over direction

Table 2

Global static pressure on platform

\begin{tabular}{lll}
\hline Platform & Direction/Parameter $\left({ }^{\circ}\right)$ & Max Pressure $(\mathrm{Pa})$ \\
\hline $\mathrm{A}$ & $0 / 180$ & $6.75 \times 10^{2}$ \\
& $225 / 315$ & $6.19 \times 10^{2}$ \\
& 270 & $6.30 \times 10^{2}$ \\
B & $0 / 180$ & $5.96 \times 10^{2}$ \\
& $225 / 315$ & $5.45 \times 10^{2}$ \\
& 270 & $5.91 \times 10^{2}$ \\
C & $0 / 180$ & $6.22 \times 10^{2}$ \\
& $225 / 315$ & $6.14 \times 10^{2}$ \\
& 270 & $6.753 \times 10^{2}$ \\
\hline
\end{tabular}




\subsection{Hydrodynamics Forces}

The fluctuation of drag and lift coefficients was determined from the forces acting on the boundary of the platform. Table 3 presents the global drag and lift force/coefficient of Platforms A, $B$, and $C$ subjected to the current flow on the seabed. The effects of the hydrodynamic coefficients and the pressure of each direction were used to create a relationship between the effect of the parameters on the scleractic coral settlement and growth. Figure 6 demonstrates the mean drag coefficient and mean lift coefficient of Platforms A, B, and C at different current directions. The graph shows that Platform $C$ was subjected to the highest mean drag coefficient of 0.399388 at $270^{\circ}$. Figure 6 also indicates that the flow direction has a significant influence on the mean lift coefficient because the value was less than 0 .

Table 3

Hydrodynamics forces on the platforms

\begin{tabular}{llllll}
\hline Platform & Direction/ Parameter $\left(^{\circ}\right)$ & $\begin{array}{l}\text { Drag Force, } F_{D} \\
(\mathrm{~N})\end{array}$ & $\begin{array}{l}\text { Mean } \\
\text { Drag Coefficient } \\
C_{D \text { mean }}\end{array}$ & $\begin{array}{l}\text { Lift Force, } F_{D} \\
(\mathrm{~N})\end{array}$ & $\begin{array}{l}\text { Mean } \\
\text { Lift Coefficient } \\
C_{L \text { mean }}\end{array}$ \\
\hline $\mathrm{A}$ & $\mathbf{0}$ & 21750.86 & 0.329807 & -107.926 & -0.00164 \\
& $225 / 315$ & 7746.886 & 0.125158 & 3818.553 & 0.061692 \\
$\mathrm{~B}$ & 270 & 24332.97 & 0.329807 & -120.917 & -0.00164 \\
& $0 / 180$ & 47649.26192 & 0.334 & -2127.345396 & -0.015 \\
& $225 / 315$ & 23159.1 & 0.134 & 7906.423 & 0.029 \\
$\mathrm{C}$ & 270 & 18594.88 & 0.351894 & -259.715 & -0.00491 \\
& $0 / 180$ & 84727.25 & 0.342728 & 1657.536 & 0.006705 \\
& $225 / 315$ & 57918.09 & 0.183175 & 10057.5 & 0.031808 \\
& 270 & 53271.72 & 0.399388 & -905.542 & -0.00679 \\
\hline
\end{tabular}
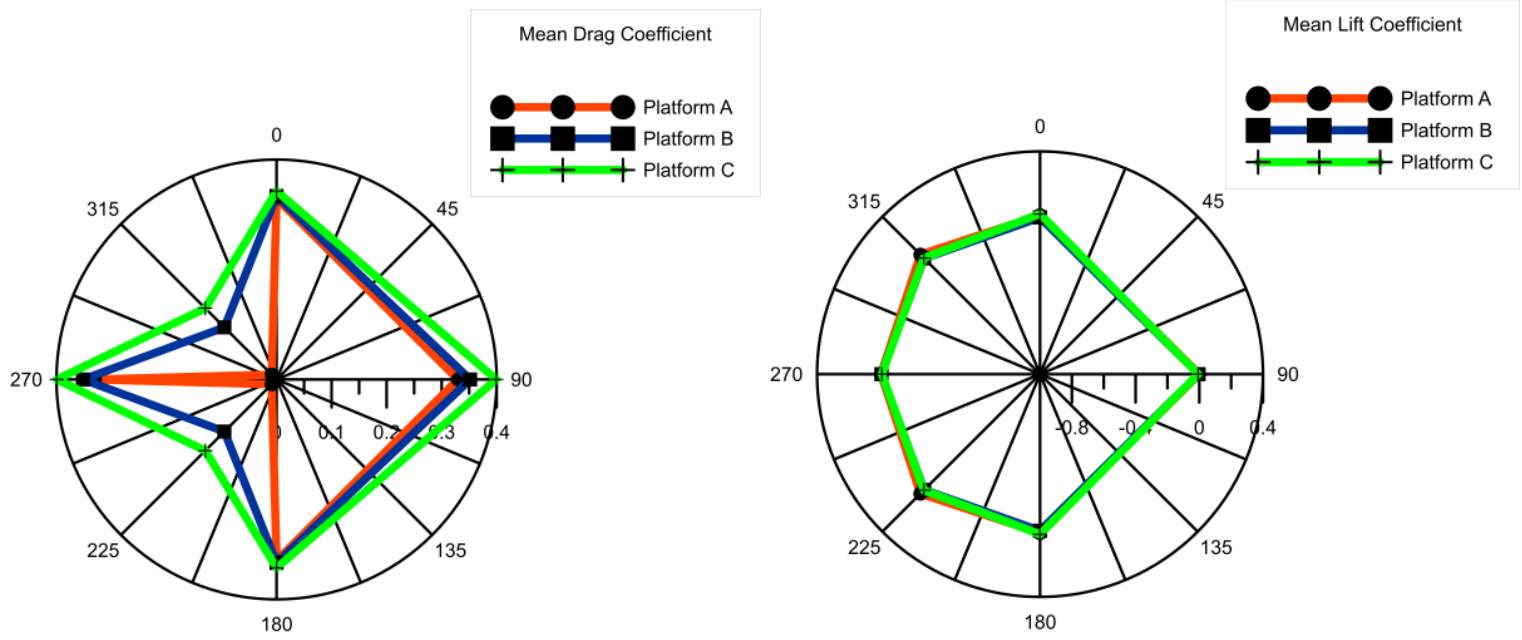

Fig. 6. Mean Drag Coefficient, $C_{D \text { mean }}$ (left) and Mean Lift Coefficient, $C_{L \text { mean }}$ (right) of the platforms at different incident angle.

\subsection{Vortex Shedding}

The local vorticity and wake profile at $x-y$ level with offset of $-61 \mathrm{~m}$ on the datum plane is illustrated in Figure 7. The dense flow and wide wake region are indicated by the flow over the platform body. Table 4 shows the frequency and Strouhal number for Platforms $A, B$, and $C$ at different current directions and Figure 8 shows the graph of shedding frequency and Strouhal number against the current directions. The highest frequency generated from vortex shedding was $0.284 \mathrm{~Hz}$ 
on Platform B at $270^{\circ}$ current direction. Low vortex shedding frequency indicates a good sign of weak chaotic effect, which would be ideal for coral larvae attachment and growth.

\section{Table 4}

Frequency and Strouhal number at different current directions

\begin{tabular}{llll}
\hline Platform & Direction $\left(^{\circ}\right)$ & Shedding Frequency, $f_{v s}(\mathrm{~Hz})$ & Strouhal Number, $S t$ \\
\hline A & $0 / 180$ & 0.107 & 3.81 \\
& $225 / 315$ & 0.149 & 3.79 \\
& 270 & 0.445 & 3.88 \\
B & $0 / 180$ & 0.055 & 3.81 \\
& $225 / 315$ & 0.149 & 3.79 \\
& 270 & 0.284 & 3.77 \\
C & $0 / 180$ & 0.046 & 3.89 \\
& $225 / 315$ & 0.078 & 3.92 \\
& 270 & 0.192 & 3.84 \\
\hline
\end{tabular}

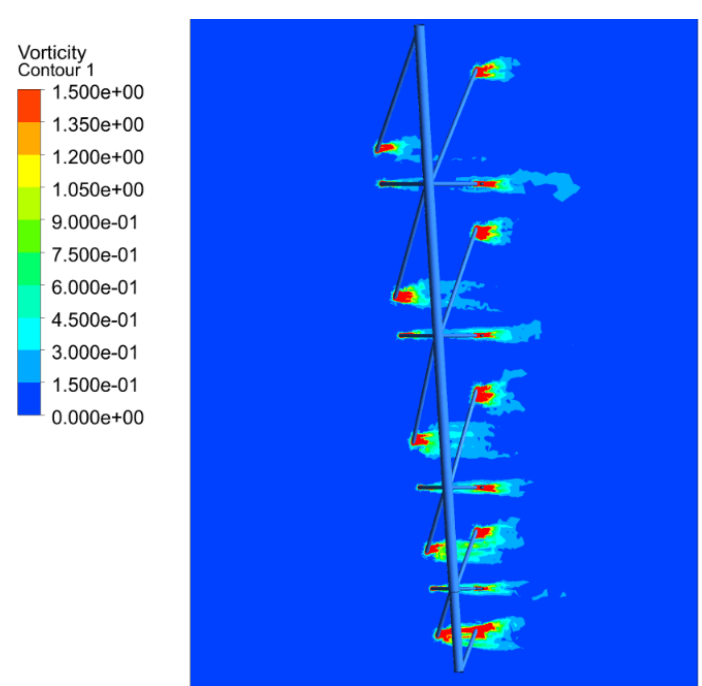

(a)

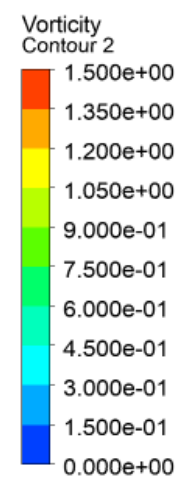

Vorticity Contour 1
$-1.000 \mathrm{e}+00$ $9.000 \mathrm{e}-01$ $8.000 \mathrm{e}-0$ $7.000 \mathrm{e}-0$ $6.000 \mathrm{e}-01$ $5.000 \mathrm{e}-01$ $4.000 \mathrm{e}-0$ $3.000 \mathrm{e}-01$ $2.000 \mathrm{e}-01$ $1.000 \mathrm{e}-0$ $0.000 \mathrm{e}+00$

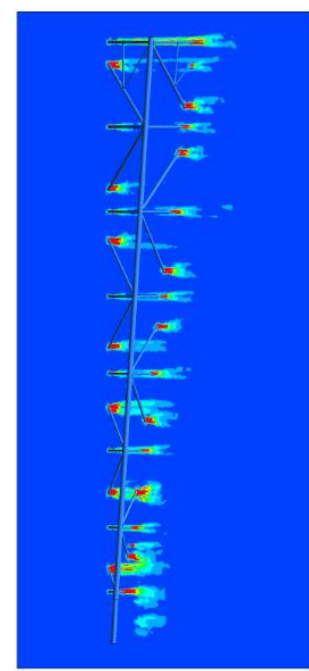

(b)

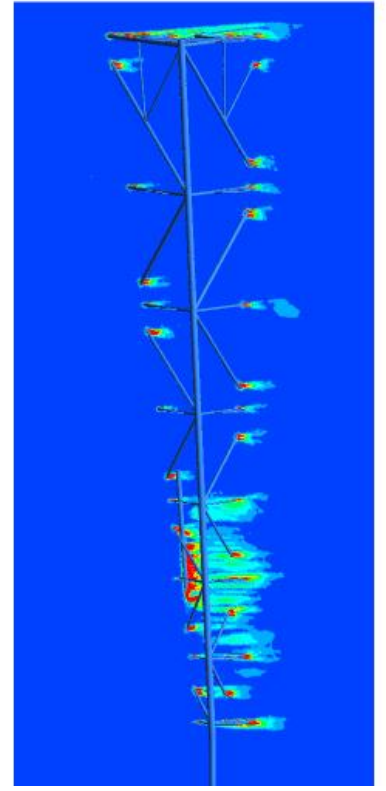

(c)

Fig. 7. Vorticity and wake region at $0^{\circ} / 180^{\circ}$ for (a) Platform A (b) Platform B (c) Platform C 

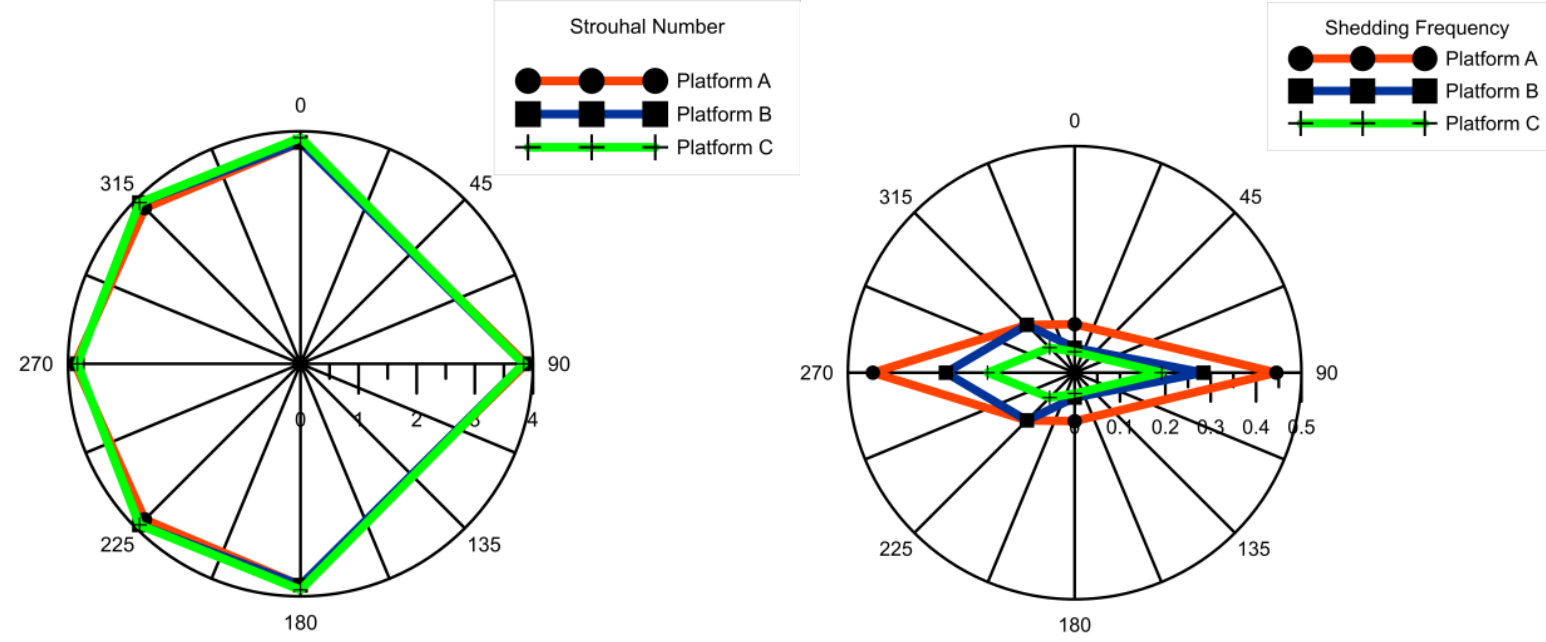

Fig. 8. Strouhal number and shedding frequency at different incident angle

\subsection{Back Eddies and Upwelling}

The efficiency index was calculated by measuring the volume of the back eddy and upwelling at the back of the structure. The back eddy velocity and upwelling volume rendering of the platforms are shown in Figures 9 and 10, respectively. Table 5 summarises the efficiency index values for the three platforms at different current directions. The values are presented in a plot as shown in Figure 11. The highest upwelling volume was $659.782 \mathrm{~m}^{3}$ at $0^{\circ} / 180^{\circ}$ current direction on Platform $A$. This shows that Platform $A$ has the potential as an artificial reef at the respective sitting position on the seabed. The upwelling flow field increases fish biological productivity by increasing the nutrient content. In the meantime, the shaded geometric region spread around and inside the reef can help algae and plankton thrive. Therefore, the artificial reefs can provide shelter from predators and abundant source of food. The highest back-eddy volume was $32.480 \mathrm{~m}^{3}$ at $0^{\circ} / 180^{\circ}$ current direction on Platform C. The back-eddy region usually provides shelter, spawning grounds, rest areas, and a temporary stopover for marine species. However, due to the simple geometry of the jacket platform, the area for marine species to stay and take shelter is insufficient.

\section{Table 5}

Efficiency index of the platforms at different current directions

\begin{tabular}{llllllll}
\hline Platform & $\begin{array}{l}\text { Direction/ } \\
\text { Parameter } \\
\left(^{\circ}\right)\end{array}$ & $\begin{array}{l}\text { Upwelling } \\
\text { velocity } \\
\text { range }(\mathrm{m} / \mathrm{s})\end{array}$ & $\begin{array}{l}\text { Back } \\
\text { eddy } \\
\text { velocity } \\
\text { range }(\mathrm{m} / \mathrm{s})\end{array}$ & $\begin{array}{l}\text { Upwelling } \\
\text { volume }\left(\mathrm{m}^{3}\right)\end{array}$ & $\begin{array}{l}\text { Back } \\
\text { eddy } \\
\text { volume }\left(\mathrm{m}^{3}\right)\end{array}$ & $\begin{array}{l}\text { Upwelling } \\
\text { efficiency } \\
\text { index, I }\end{array}$ & $\begin{array}{l}\text { Back eddy } \\
\text { efficiency } \\
\text { index, I }\end{array}$ \\
\hline A & $0 / 180$ & $1.155-2.794$ & $0.00-0.605$ & 659.782 & 6.6732 & 13.7411 & 0.138 \\
& $225 / 315$ & $1.155-2.33$ & $0.00-0.605$ & 66.4686 & 3.7156 & 1.3843 & 0.077 \\
& 270 & $1.155-1.897$ & $0.00-0.605$ & 18.2962 & 0.6258 & 0.3803 & 0.013 \\
B & $0 / 180$ & $1.144-2.223$ & $0.00-0.572$ & 263.902 & 15.561 & 2.386 & 0.1407 \\
& $225 / 315$ & $1.144-1.920$ & $0.00-0.572$ & 59.901 & 3.6591 & 0.542 & 0.0330 \\
C & 270 & $1.144-2.006$ & $0.00-0.572$ & 24.406 & 9.4674 & 0.220 & 0.0861 \\
& $0 / 180$ & $1.166-2.355$ & $0.0-0.583$ & 508.220 & 32.480 & 2.0953 & 0.13391 \\
& $225 / 315$ & $1.166-1.955$ & $0.0-0.583$ & 158.597 & 12.770 & 0.6538 & 0.052 \\
\end{tabular}


Top view

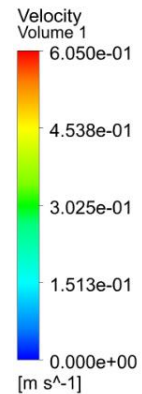

$\left[\mathrm{m} \mathrm{s}^{\wedge}-1\right]$
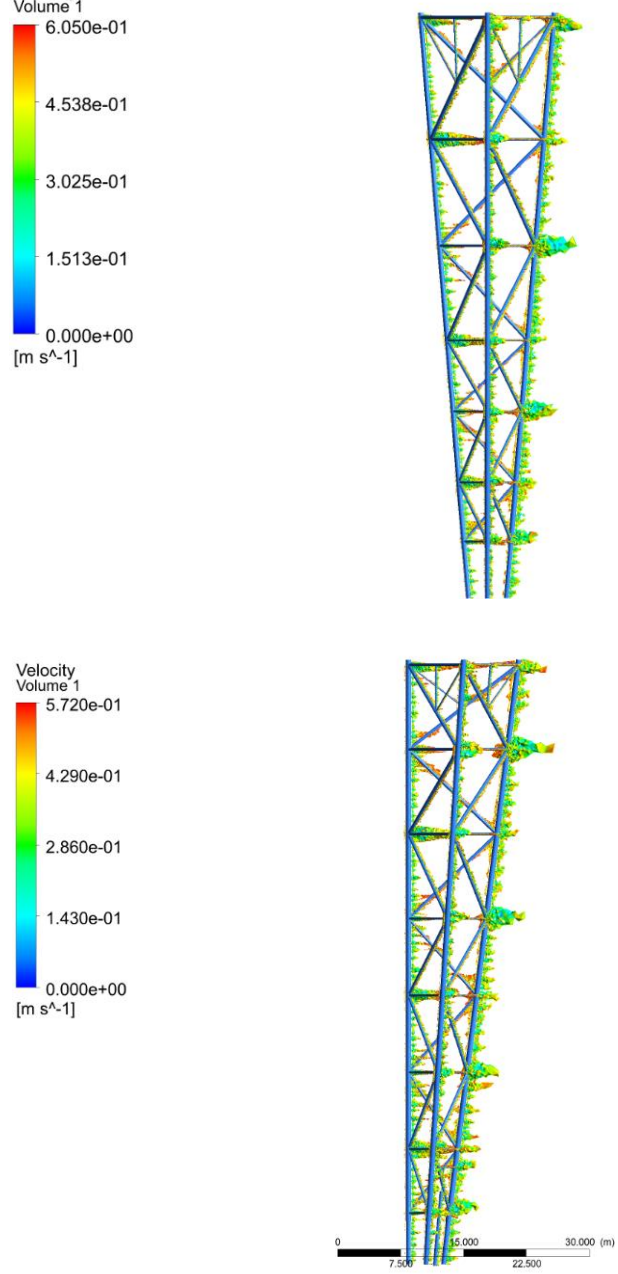

Velocity
Volume 1

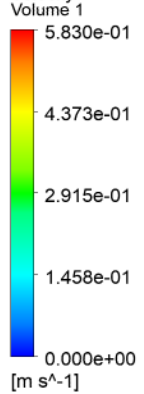

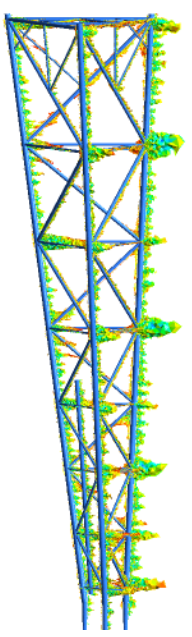

Front view

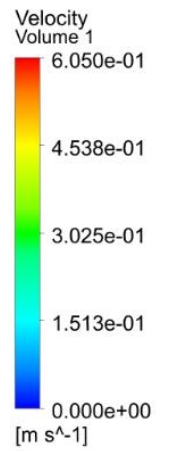

(a)
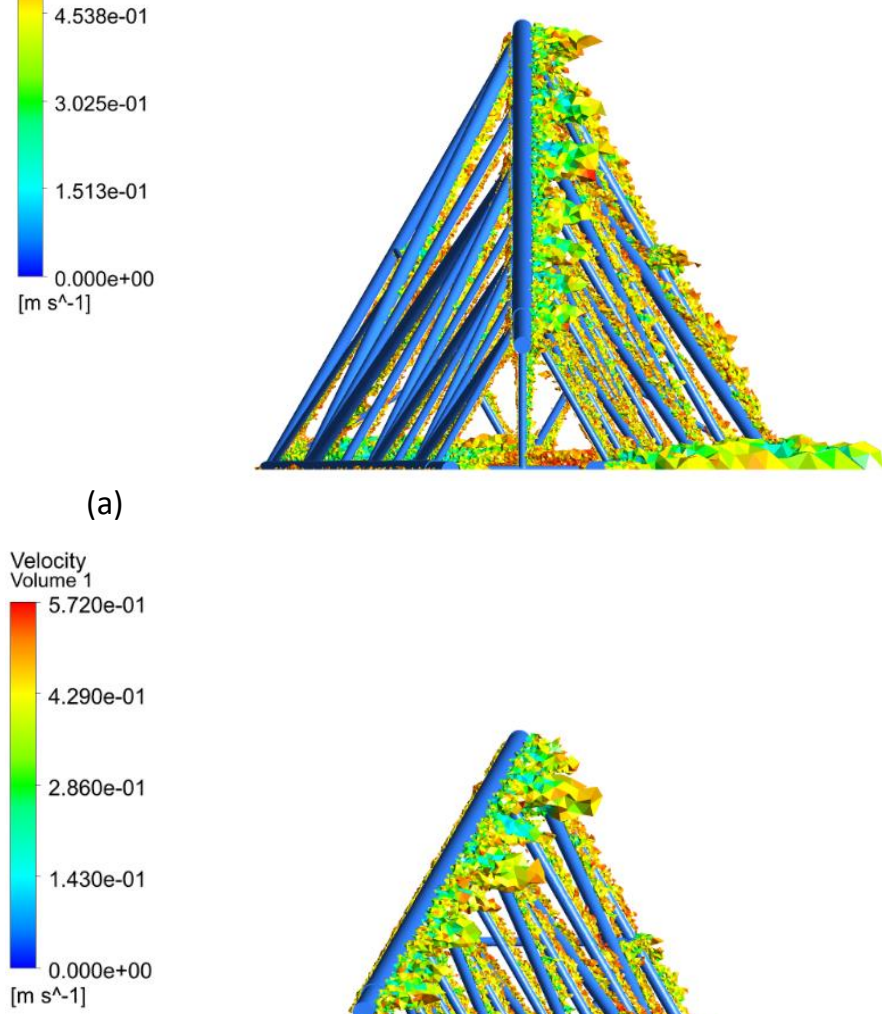

(b)
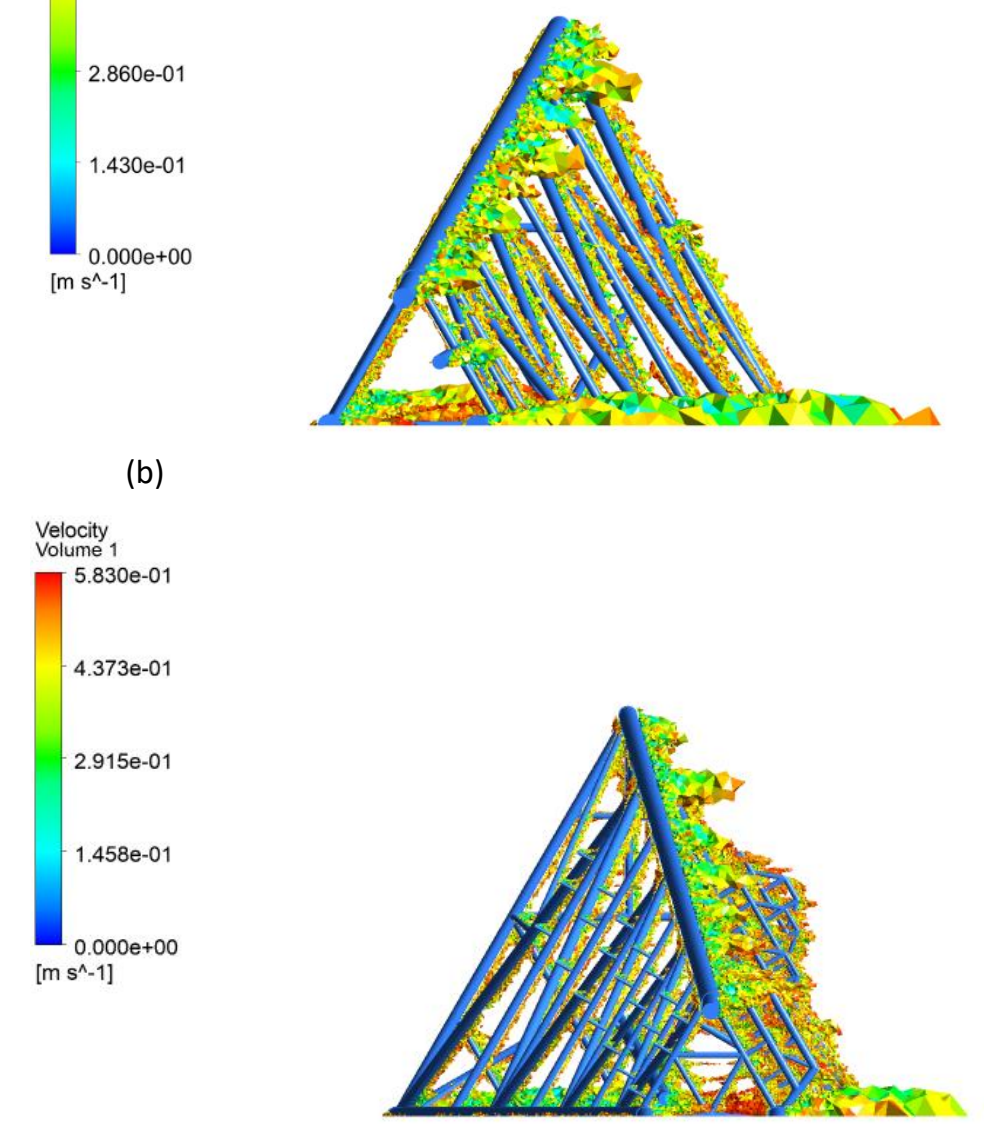

(c)

Fig. 9. The top (left) and front (right) views of back eddies volume profile at $0^{\circ} / 180^{\circ}$ for (a) Platform A (b) Platform B (c) Platform C. 

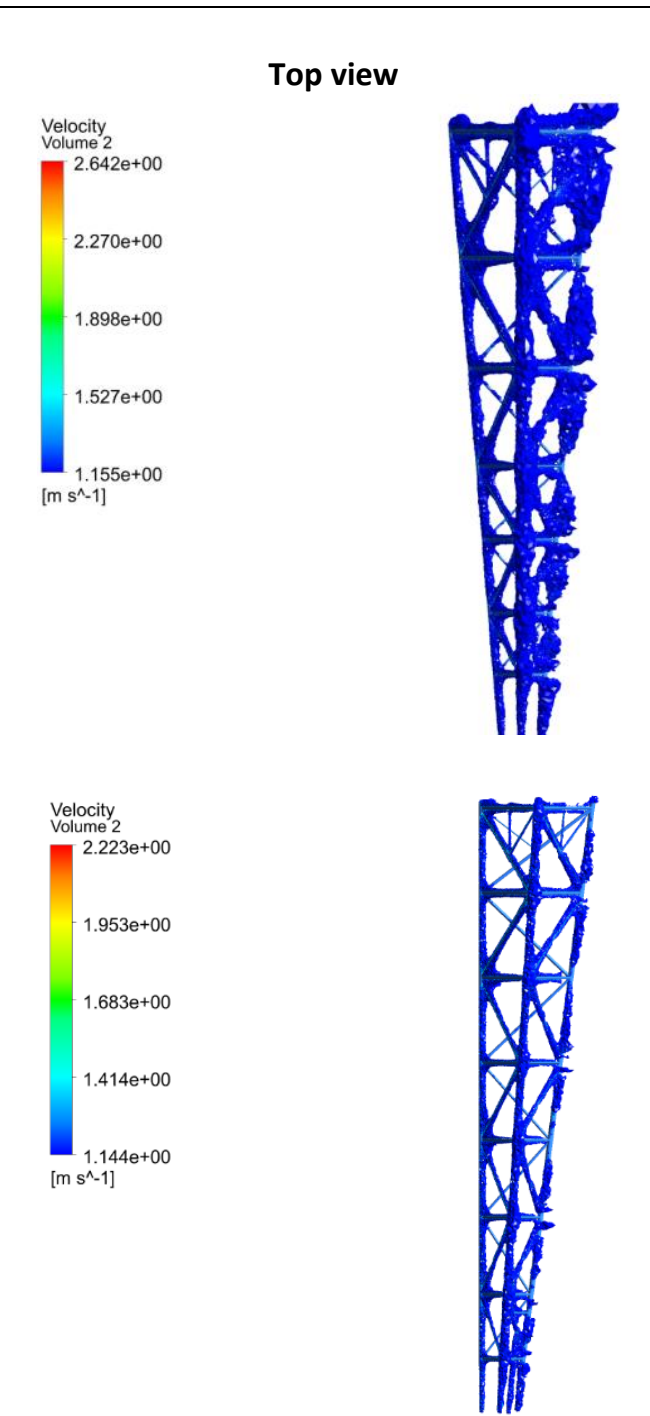

(a)
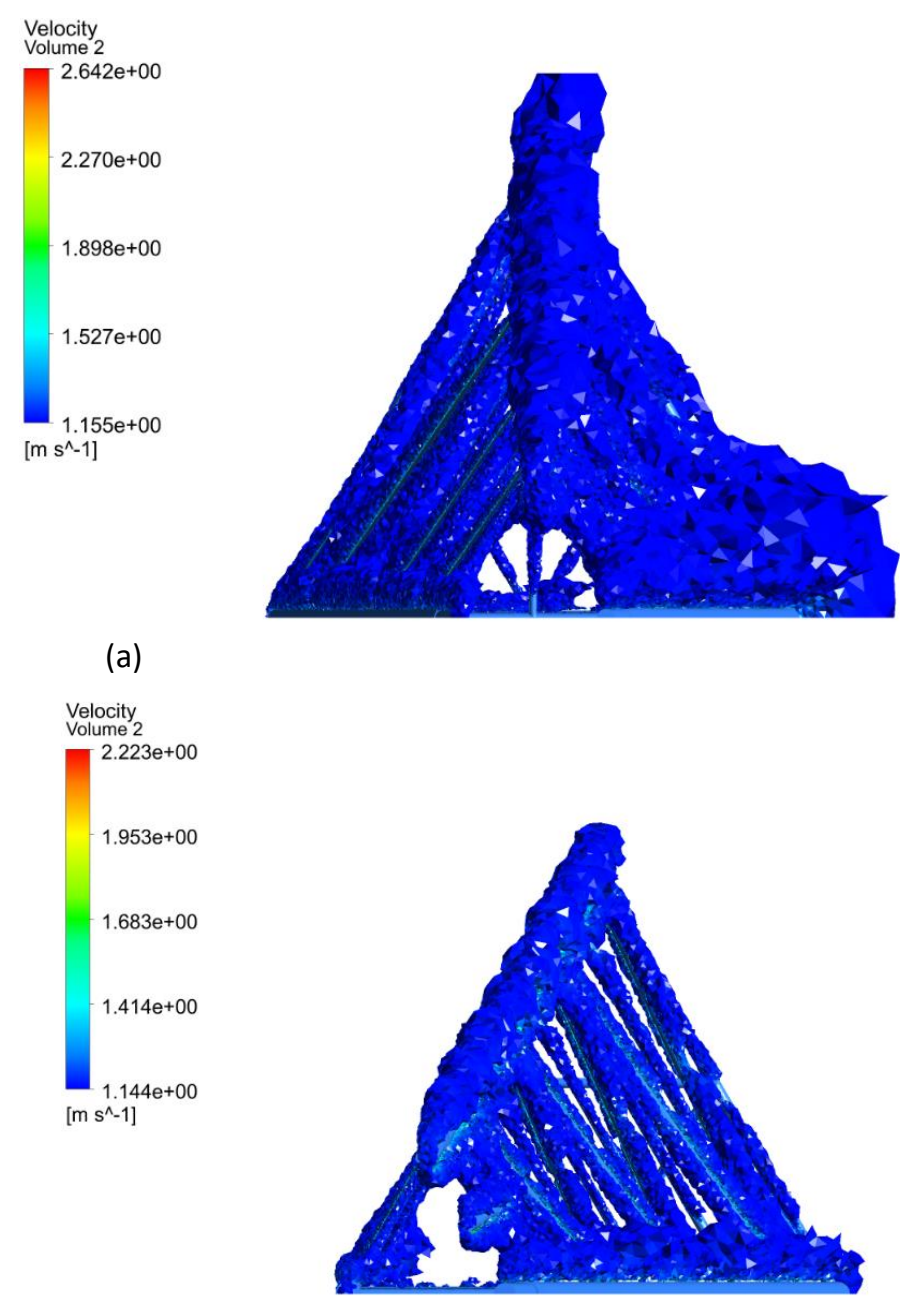

(b)
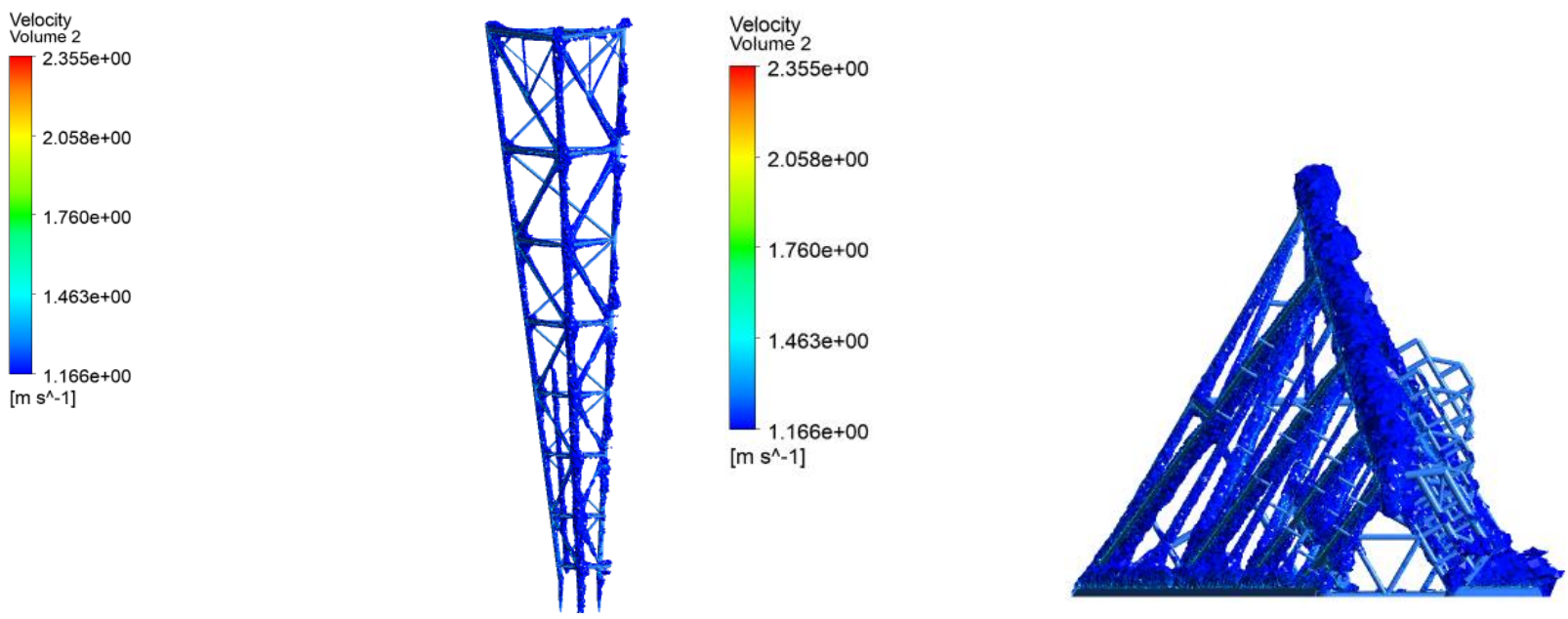

(c)

Fig. 10. The top (left) and front (right) views of upwelling volume profile at $0^{\circ} / 180^{\circ}$ for (a) Platform $A$ (b) Platform B (c) Platform C. 

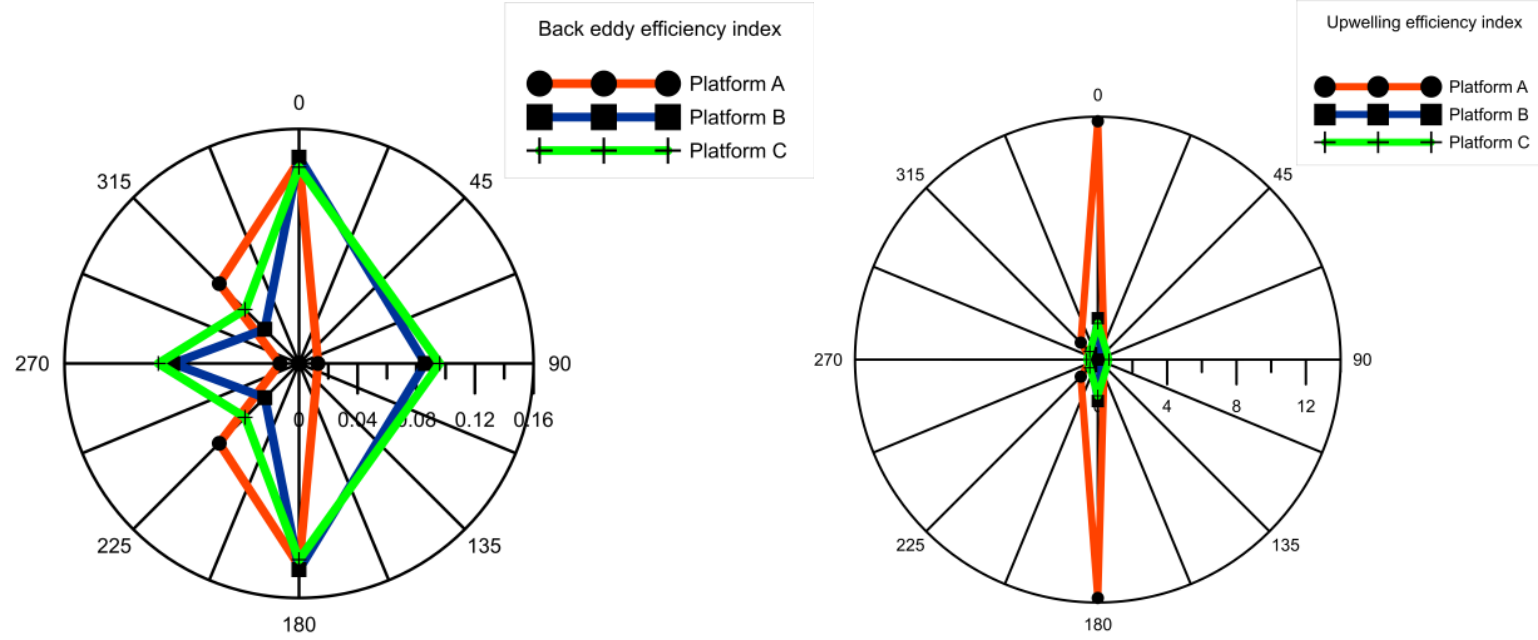

Fig. 11. Back eddy (left) and upwelling (Right) Efficiency Index at different incident angle.

\section{Conclusions}

This paper has presented the CFD analysis of R2R jacket platform to investigate the performance of the artificial reefs. Few governing factors were studied to understand the ability of the platform as a new reef for corals and home for marine life. Based on the simulation of jacket platform for R2R on the seabed, it can be concluded that as to present conditions studied, the platform is suitable for coral larvae to attach and grow. The higher efficiency index shows the higher chance of the artificial reef to be successful to attract settlement of the benthic and fishes on the platform. The position of the jacket platform was proposed to be at normal direction to the flow because higher upwelling and back eddies could be generated around the jacket platform. This would eventually increase the jacket platform performance as an artificial reef.

\section{Acknowledgement}

This research was funded by a grant from Ministry of Higher Education of Malaysia (FRGS Grant VOT59417).

\section{References}

[1] Liu, Tsung-Lung, and Dong-Taur Su. "Numerical analysis of the influence of reef arrangements on artificial reef flow fields." Ocean Engineering 74 (2013): 81-89. https://doi.org/10.1016/i.oceaneng.2013.09.006

[2] Awang Daud. "Oil Rig As Artificial Reef: Example of Baram 8." Fisheries Research Institute Sarawak Branch (2013). https://doi.org/10.13140/RG.2.2.36098.89283

[3] Yaakob, Omar B., Yasser M. Ahmed, M. Rajali Jalal, A. A. Faizul, Koh K. Koh, and Tarmizi J. Zaid. "Hydrodynamic Design of New Type of Artificial Reefs." In Applied Mechanics and Materials, vol. 819, pp. 406-419. Trans Tech Publications Ltd, 2016. https://doi.org/10.4028/www.scientific.net/AMM.819.406

[4] Daud, Nurul Rabitah, Mohd Fadzil Akhir, and Mohd Lokman Husain. "Water circulation in the shallow shelf areas off the Terengganu coast affected by wind stress force using a hydrodynamic model." In Journal of Sustainability Science and Management Special Issue Number 1: The International Seminar on the Straits of Malacca and the South China Sea, pp. 81-92. 2016.

[5] Sumer, B. Mutlu, and Rolf Deigaard. "Particle motions near the bottom in turbulent flow in an open channel. Part 2." Journal of Fluid Mechanics 109 (1981): 311-337. https://doi.org/10.1017/S0022112081001092

[6] Lee, Sing-Kwan, Hung-Pin Chien, and Hai Gu. "CFD study of deep draft semisubmersible VIM." In Offshore Technology Conference-Asia. Offshore Technology Conference, 2014.

https://doi.org/10.4043/24766-MS 
[7] Dandan, Muhammad Arif, Syahrullail Samion, Mohamad Nor Musa, and Fazila M. Zawawi. "Evaluation of Lift and Drag Force of Outward Dimple Cylinder Using Wind Tunnel." CFD Letters 11, no. 3 (2019): 145-153.

[8] Pranesh, C., M. Sivapragasam, M. D. Deshpande, and H. K. Narahari. "Negative lift characteristics of NACA 0012 aerofoil at low Reynolds numbers." Sādhanā 44, no. 1 (2019): 21.

https://doi.org/10.1007/s12046-018-1008-6

[9] Bull, Ann Scarborough, and Milton S. Love. "Worldwide oil and gas platform decommissioning: a review of practices and reefing options." Ocean \& coastal management 168 (2019): 274-306. https://doi.org/10.1016/i.ocecoaman.2018.10.024

[10] Yoon, Dong-Hyeog, Kyung-Soo Yang, and Choon-Bum Choi. "Flow past a square cylinder with an angle of incidence." Physics of fluids 22, no. 4 (2010): 043603.

https://doi.org/10.1063/1.3388857

[11] Oliveira, Dinis, and Lena Granhag. "Matching forces applied in underwater hull cleaning with adhesion strength of marine organisms." Journal of Marine Science and Engineering 4, no. 4 (2016): 66. https://doi.org/10.3390/jmse4040066

[12] Sommer, Brigitte, Ashley M. Fowler, Peter I. Macreadie, David A. Palandro, Azivy C. Aziz, and David J. Booth. "Decommissioning of offshore oil and gas structures-Environmental opportunities and challenges." Science of the total environment 658 (2019): 973-981. https://doi.org/10.1016/i.scitotenv.2018.12.193

[13] Yonemoto, Koichi, Keiichiro Takato, Hiroshi Ochi, and Satoshi Fujie. "Kutta condition violation in two-dimensional NACA0012 airfoil at low Reynolds number." In 26th AIAA Applied Aerodynamics Conference, p. 6399. 2008. https://doi.org/10.2514/6.2008-6399

[14] Tsukamoto, K., T. Kawamura, T. Takeuchi, T. D. Beard Jr, and M. J. Kaiser. "Coastal artificial habitats for fishery and environmental management and scientific advancement." In Fisheries for Global Welfare and Environment, 5th World Fisheries Congress, pp. 335-349. 2008.

[15] Lowry, M. B., T. M. Glasby, C. A. Boys, H. Folpp, I. Suthers, and M. Gregson. "Response of fish communities to the deployment of estuarine artificial reefs for fisheries enhancement." Fisheries Management and Ecology 21, no. 1 (2014): 42-56. https://doi.org/10.1111/fme.12048

[16] Kim, Dongha, Jinho Woo, Han-Sam Yoon, and Won-Bae Na. "Wake lengths and structural responses of Korean general artificial reefs." Ocean Engineering 92 (2014): 83-91.

https://doi.org/10.1016/j.oceaneng.2014.09.040

[17] Kim, Dongha, Jinho Woo, Han-Sam Yoon, and Won-Bae Na. " Efficiency, tranquillity and stability indices to evaluate performance in the artificial reef wake region." Ocean Engineering 122 (2016): 253-261. https://doi.org/10.1016/j.oceaneng.2016.06.030

[18] Wang, Gang, Rong Wan, XinXin Wang, FenFang Zhao, XiaoZheng Lan, Hui Cheng, WeiYao Tang, and QingLong Guan. "Study on the influence of cut-opening ratio, cut-opening shape, and cut-opening number on the flow field of a cubic artificial reef." Ocean Engineering 162 (2018): 341-352.

https://doi.org/10.1016/i.oceaneng.2018.05.007

[19] Mohd Asamudin A. Rahman, Muhammad Nadzrin Nazri, Ahmad Fitriadhy, Mohammad Fadhli Ahmad, Erwan Hafizi Kasiman, Mohd Azlan Musa, Fatin Alias, and Mohd Hairil Mohd. "A Fundamental CFD Investigation of Offshore Structures for Artificial Coral Reef Development." CFD Letters 12, no. 7 (2020): 110-125. https://doi.org/10.37934/cfdl.12.7.110125 